\title{
Suction sampling of grassland invertebrates using the G-vac: Quantifying and avoiding peripheral suction effects
}

\author{
ANDREw CHERRILL \\ Entomology Research Group, Crop and Environment Sciences, Harper Adams University, Edgmond, Shropshire TF10 8NB, UK; \\ e-mail: acherrill@harper-adams.ac.uk
}

Key words. Hemiptera, Auchenorrhyncha, vacuum sampling, peripheral suction effect, D-vac, G-vac, Vortis

\begin{abstract}
Suction sampling with modified garden leaf-blowers (G-vacs) is a widely used method for research on invertebrates in agricultural and grassland habitats. Approaches vary from sweeping the collecting nozzle across the surface of the vegetation within a known area, applying the nozzle firmly to the ground to delimit a sample area equal to nozzle crosssection, or applying the nozzle repeatedly within a larger open-ended cylinder placed on the ground. These approaches vary in potential for the inadvertent capture of specimens from outside of the sample area as a result of air being drawn into the nozzle from adjacent vegetation. This has never been studied adequately and is defined here for the first time as the Peripheral Suction Effect (PSE). Invertebrate species are likely to differ in susceptibility to PSE and so both sample size and composition could be impacted. This study compares two series of samples of Auchenorrhyncha taken using the same G-vac suction sampler (nozzle area, $0.01 \mathrm{~m}^{2}$ ) from areas enclosed and unenclosed by an openended cylindrical enclosure (area $0.17 \mathrm{~m}^{2}$ ) intended to prevent PSE. The unenclosed samples contained greater numbers of leafhoppers including Arthaldeus pascuellus, Javesella pellucida and immature Deltocephalinae. Numbers of immature Delphacinae did not differ between enclosed and unenclosed samples. The species composition of the two series of samples was similar, but the proportional representation of immature Delphacinae in unenclosed samples was diluted by the inflated numbers of other taxa that were drawn from the surrounding area. Peripheral suction effects are taxa-specific and therefore have the potential to bias measures of invertebrate community composition. Use of an open-ended cylinder to delimit the sample area is recommended as a simple, inexpensive and effective method of avoiding problems associated with PSE when using a G-vac. The potential for PSE with other models of suction samplers is discussed and questions for further research are identified.
\end{abstract}

\section{INTRODUCTION}

Suction samplers are widely used in entomological research in grassland and agricultural systems (Macleod et al., 1994; Samu et al., 1997; Standen, 2000). Key determinants of the numbers and species of invertebrates collected are nozzle diameter, suction power, vegetation structure, weather and the characteristics of the target organisms (Henderson \& Whitaker, 1977; Hossain et al., 1999; Bell et al., 2002; Sanders \& Entling, 2011). Various types of apparatus are available with modified garden leaf blowervacuum apparatus, commonly known as a G-vacs, being used widely (Stewart, 2002).

Suction samples using G-vacs are routinely collected using one or other of three approaches (Stewart, 2002). The simplest approach has been to sweep the nozzle across the surface of the vegetation within a defined area (e.g. Elliot et al., 2006; Doxon et al., 2011). A second approach has been to apply the nozzle of the apparatus flat against the ground for a given time period. This area, equal to the cross-sectional area of the nozzle, is then regarded as the basic sample unit, although often a series of such "touchdowns" are pooled to give a single sample of larger area (e.g. Macleod et al., 1994; Samu \& Sarospataki, 1995; Bell et al., 2000; Nickel \& Hildebrandt, 2003). A third approach has been to sample within an open ended cylinder placed on the ground immediately before sampling (e.g. Stewart \& Wright, 1995; Hossain et al., 1999; Littlewood et al.,
2006, 2009). The sample is then taken by repeatedly applying the nozzle within the cylinder until the whole area has been covered. Sampling from within a cylinder has the potential advantage that the inadvertent capture of specimens from outside of the sample area is prevented (Stewart \& Wright, 1995). The term Peripheral Suction Effect (PSE) is proposed here for the first time to describe this problem. PSE is defined as the capture of specimens from outside of the sample area as a result of air (and material) being drawn into the nozzle from adjacent surfaces. PSE can occur because of an incomplete seal between the nozzle and the surface being sampled and when the nozzle is raised and lowered during sampling.

To date there has been no adequately designed study of PSE to determine unequivocally the existence and magnitude of such an effect. As outlined above, sampling cylinders have been used to delimit sample areas in some, but not all studies. Quantitative information is therefore required to determine the extent to which catch size and composition may be influenced by the use or otherwise of a sampling cylinder, thereby guiding best practice in future studies.

In the present study, a comparison is made between samples of Auchenorryncha taken using a G-vac with and without the use of a sampling cylinder to control PSE. The results show that both catch-size and species-composition are influenced by use of a sampling cylinder with the Gvac. The implications for sampling, and further research, 
are discussed both for the use of G-vacs, but also other vacuum sampling apparatus where the risks of PSE are likely to differ.

\section{MATERIAL AND METHODS}

The study was carried out at Harper Adams University, Shropshire, England, UK (Latitude $52^{\circ} 78^{\prime} \mathrm{N}$, Longitude $2^{\circ} 43^{\prime} \mathrm{W}$ ). The grassland was a sown representative of Lolium perenne-Cynosurus cristatus, Typical sub-community, MG6a in the UK National Vegetation Classification (Rodwell, 1992). Based on a series of ten $0.25 \mathrm{~m}^{2}$ quadrats, the mean covers of the most abundant species occurring in more than half of quadrats were $L$. perenne $55.8 \%(\mathrm{SD}=16.3)$, Cynosurus cristatus $23.0 \%(\mathrm{SD}=16.5)$ and Agrostis stolonifera $7.2 \%$ (10.2). The grassland was established five years previously and is mown with the first cut typically in mid-July. The pasture was selected because of its uniformity of composition and height structure. Mean height, assessed using a drop plate (Cherrill \& Rushton, 1993), was $16.5 \mathrm{~cm}$ (SD = 3.75, $\mathrm{N}=30$ ). The sward was sufficiently open that placement of the sampling cylinder and suction nozzle could be achieved without pressing the vegetation flat against the ground.

The suction sampler was a modified McCulloch GBV 325 garden blower/vacuum commonly referred to as a G-vac (Stewart $\&$ Wright, 1995, Stewart, 2002). The end of the collecting pipe was sawn off perpendicular to its length and had a cross sectional area of $0.011 \mathrm{~m}^{2}$. All samples were taken from a standard sample area of $0.174 \mathrm{~m}^{2}$ defined by the internal area of a rigid plastic drain pipe (diameter $47 \mathrm{~cm}$ ). A section $60 \mathrm{~cm}$ in length and approximately $5 \mathrm{~kg}$ in weight was used as the sampling cylinder. To ensure an equal area was used for unenclosed samples, a $3 \mathrm{~cm}$ ring was cut from the same pipe.

Samples were taken between 13:00 and 15:00 on $9^{\text {th }}$ July 2013. Air temperature $1 \mathrm{~m}$ above ground at $13: 00$ was $27^{\circ} \mathrm{C}$ and fluctuated by only $2^{\circ} \mathrm{C}$. The vegetation, leaf litter and soil surface were dry. There was no wind. Cloud cover was zero.

Samples were taken at intervals of $2 \mathrm{~m}$ along two parallel $80 \mathrm{~m}$ transects separated by $5 \mathrm{~m}$. Samples that were enclosed and unenclosed by the cylinder were taken alternately along each transect by the same operator. Twenty enclosed and 20 unenclosed samples were taken ( 10 of each per transect). Each sample was taken by placing the cylinder or ring on the ground and then immediately applying the suction sampler for $30 \mathrm{~s}$. The motor was run at full throttle from when the nozzle was first lowered on to the ground. The nozzle was held in place for 1 to $2 \mathrm{~s}$ before being raised rapidly to approximately two-thirds the height of the grass sward (i.e. approximately $10-15 \mathrm{~cm}$ above ground level) and then lowered immediately to an adjacent and partially overlapping position within the sample area. The motor was run at full throttle as it was raised from each touch-down to prevent escape of specimens from the net as is standard practice with G-vac samplers (Stewart \& Wright, 1995). After 30 s of this repeated "touch-down" sampling the whole $0.17 \mathrm{~m}^{2}$ sample area was covered.

The "touch-down" duration was based on studies showing that over $90 \%$ of specimens are usually captured within the first second (Bell et al., 2002; Brook et al., 2008). Other studies have frequently used periods of $5 \mathrm{~s}$ or $10 \mathrm{~s}$ (e.g. Nickel \& Hildebrandt, 2003; Hollier et al., 2005). The total sampling duration of $30 \mathrm{~s}$ was also based on previous studies. For example Stewart \& Wright (1995) used a sample period $20 \mathrm{~s}$ with an enclosed area of $0.1 \mathrm{~m}^{2}$, while Hossain et al. (1999) used periods of both $90 \mathrm{~s}$ and $120 \mathrm{~s}$ within enclosed areas of $0.2 \mathrm{~m}^{2}$. Longer touch-downs and total sample periods may have increased marginally the proportion of invertebrates collected from within the nozzle area, whilst increasing the probability of PSE. Sampling periods were designed to be relatively conservative so as not to inflate the risk of PSE.

At the end of each $30 \mathrm{~s}$ sample period, the nozzle was raised clear of the vegetation and the motor was allowed to idle while the net was emptied into a cotton bag. The net was turned inside out before being reattached within the nozzle of the suction sampler. Reversing the net ensured that cross-contamination of successive samples was impossible.

Samples were stored within a cool box in the field before being frozen. After sorting Aunchenorrhycha were stored in 70\% methanol and identified using Biedermann \& Niedringhaus (2009). Remaining invertebrate, plant and soil material (henceforth labelled debris) was refrozen. After all samples had been sorted, debris was air dried for six weeks at room temperature and weighed to $0.001 \mathrm{~g}$.

Statistical analysis used Pearson's correlation and Student's ttest for independent samples. Variables that did not conform to a normal distribution, and which could not be transformed to meet this assumption, were analysed using an equivalent non-parametric test.

\section{RESULTS}

In total, 1543 leafhoppers were collected. Nine species were identified and a large number of immature specimens were classified to sub-family (Table 1).

Mean numbers of all leafhoppers, and numbers of Arthaldeus pascuellus, Javesella pellucida and immature Deltocephalinae, were greater in unenclosed samples than enclosed samples (Table 1). The number of immature Delphacinae, number of species and weight of debris did not differ between the two sets of samples. Species composition was also broadly comparable. However, the proportional representation of immature Delphacinae in unenclosed samples was diluted by the presence of other taxa drawn in from outside of the sampling area. In enclosed samples, immature Delphacinae made up a higher mean proportion of all specimens (mean $=46.4 \%, \mathrm{SD}=18.7$ ), compared with in unenclosed samples $(36.1 \%, \mathrm{SD}=14.1)$ (t-test using arcsin transformed data, $\mathrm{P}=0.05$ ). As a percentage of the total numbers captured immature Delphacinae were $52.1 \%(\mathrm{~N}=612)$ and $37.2 \%(\mathrm{~N}=922)$ of those from enclosed and unenclosed samples respectively.

There was no correlation between the weight of debris and numbers of leafhoppers either overall $(\mathrm{r}=0.12, \mathrm{P}=$ $0.47)$ or for enclosed $(\mathrm{r}=0.40, \mathrm{P}=0.08)$ or unenclosed samples $(\mathrm{r}=-0.04, \mathrm{P}=0.88)$ considered separately.

\section{DISCUSSION}

Stewart (2002) reviewed vacuum sampling methods for grassland Auchenorrhyncha and highlighted the risk of specimens being sucked up from adjacent vegetation. However, the extent of this effect, defined here for the first time as the Peripheral Suction Effect (PSE), has not been studied in detail. I am aware of only two studies that relate directly to the issue. In the first study, Duffey (1974) compared grassland invertebrates from two series of samples of equal area made using a Dietrick vacumm sampler (D-vac) with a collecting nozzle of approximately $0.09 \mathrm{~m}^{2}$. One series comprised the catch from nine quadrats, each $1 \mathrm{~m}^{2}$ and lacking a side-wall, from within which 
TABLE 1. Mean weight of debris and average number of leafhopper individuals and species obtained by suction sampling within enclosed and unenclosed areas $(n=20$ in each case).

\begin{tabular}{|c|c|c|c|c|c|}
\hline & \multicolumn{2}{|c|}{ Enclosed } & \multicolumn{2}{|c|}{ Unenclosed } & \multirow{2}{*}{$\begin{array}{c}\text { Comparison between } \\
\text { groups }(\mathrm{P})\end{array}$} \\
\hline & Mean & SD & Mean & SD & \\
\hline \multicolumn{6}{|l|}{ Adult specimens } \\
\hline Philaenus spumarius & 0.05 & 0.22 & 0.05 & 0.22 & - \\
\hline Neophilaenus lineatus & 0.05 & 0.22 & 0.0 & 0.0 & - \\
\hline Javesella pellucida & 0.80 & 1.20 & 2.90 & 1.92 & $<0.001$ \\
\hline Arthaldeus pascuellus & 6.45 & 4.41 & 11.45 & 7.46 & 0.014 \\
\hline Streptanus sordidus & 0.35 & 0.81 & 0.60 & 1.10 & - \\
\hline Euscelis incisus & 0.15 & 0.49 & 0.25 & 0.55 & - \\
\hline Cicadula persimilis & 0.05 & 0.22 & 0.0 & 0.0 & - \\
\hline Zyginidia scutellaris & 0.10 & 0.31 & 0.0 & 0.0 & - \\
\hline \multicolumn{6}{|l|}{ Immature specimens } \\
\hline Delphacinae* & 15.95 & 13.88 & 17.30 & 10.77 & 0.48 \\
\hline Deltocephalinae* & 6.65 & 4.55 & 14.00 & 7.11 & $<0.001$ \\
\hline Total number of individuals & 30.60 & 17.67 & 46.55 & 18.68 & 0.009 \\
\hline Number of species & 1.95 & 0.76 & 2.35 & 0.75 & 0.10 \\
\hline Weight of debris and by-catch $(\mathrm{g})$ & 3.55 & 1.36 & 3.16 & 0.96 & 0.31 \\
\hline
\end{tabular}

Comparison between groups used Student's t-test except for J. pellucida for which Mann-Whitney U-test was used because data could not be transformed to meet assumptions. No analysis was performed where the total number of individuals was less than $20 ; *$ indicates that data was square-root transformed prior to analysis.

contiguous touch-down samples were taken. The second series comprised nine samples of $1 \mathrm{~m}^{2}$ each obtained by pooling the catch from eleven widely-spaced touch-downs. This second series contained significantly greater numbers of Coleoptera, Diptera, Hymenoptera and Homoptera. In the second study, Samu et al. (1997) investigated the density of spiders within an alfalfa crop. They used a G-vac with a nozzle area of $0.01 \mathrm{~m}^{2}$ and compared a series of 48 standard "touch-down" samples with those taken by applying the same nozzle repeatedly within a $0.5 \mathrm{~m}$ high metal cylinder with an area of $0.48 \mathrm{~m}^{2}$. The large cylinder and series of smaller samples had the same total area, yet more spiders were found in the latter. The results from both studies were interpreted as being caused by additional animals being drawn from adjacent vegetation into the smaller sub-samples which had much larger total perimeter-to-area ratios. Whilst this conclusion is intuitive, a scientifically rigorous investigation would involve a comparison of sampling strategies that are identical in terms of the perimeterto-area ratio, but different in terms of the presence or absence of an experimental manipulation to prevent capture of specimens from adjacent vegetation. Samu et al. (1997), used a sampling cylinder in one series of samples, but the use of the cylinder was confounded with a seven-fold difference in total perimeter length between treatments. As shown by Duffey (1974) more spiders might have been anticipated from the series of smaller samples even if the cylinder had not been used. Samu et al. (1997) has been cited widely as evidence for the capture of specimens from adjacent vegetation (defined here as PSE) (Stewart, 2002), but the sampling design was not appropriate to allow an assessment of its importance due to the confounding effects of variation in perimeter-to-area ratios.

The present study is the first to circumvent the problem of confounding sample perimeter-to-area ratio effects in the investigation of PSE. Enclosed and unenclosed samples were identical in area and perimeter and differed only in the presence/absence of the cylinder. The cylinder was designed to prevent capture of invertebrates from outside of the stated sample area. The results show an effect on numbers of Auchenorrhyncha captured and support the view that suction sampling can inadvertently draw in numbers from outside of the sample area to inflate the sample size. Moreover, the effect of PSE was not consistent for all taxa. Numbers of immature Delphacinae showed no difference between sample types, but immature Delphacinae represented a greater proportion of all specimens in enclosed compared with unenclosed samples. Their numbers were diluted by other taxa drawn from beyond the sample area within unenclosed samples. Measures of invertebrate community composition, such as proportional diversity indices, may therefore also be biased by PSE.

The results are particularly pertinent for use of G-vacs and D-vacs because many authors have pooled series of sub-samples to increase sample area and catch (Nickel \& Hildebrandt, 2003; Hines et al., 2005). Moreover, not all studies using a G-vac utilise a sampling cylinder (Macleod et al., 1994; Samu \& Sarospataki, 1995; Bell et al., 2002) and this would be the exception for application of a D-vac (e.g. Morris et al., 2005). Nickel \& Hildebrandt (2003), for example, defined a G-vac sample as the pooled catch from ten widely-spaced touch-downs of $0.015 \mathrm{~m}^{2}$ each defined by the nozzle of their machine. These ten touch-downs had a combined perimeter of $4.3 \mathrm{~m}$, while a single circle with the same total area has a perimeter of only $1.4 \mathrm{~m}$. The potential for PSE may therefore be greater than is apparent from a consideration of total sample area alone.

On balance PSE is likely to be less of a concern with a D-vac compared to a G-vac because the former has a larger nozzle with lower perimeter-to-area ratio. The suction pow- 
er of a D-vac is also considerably lower than most modern G-vacs (Stewart, 2002). It is therefore predicted that PSE will be smaller for a D-vac than for a G-vac, although this awaits experimental verification. The relevance of the present study to use of Vortis suction samplers (manufactured by Burkard, UK) also warrants consideration. Sampling using the Vortis typically involves pooling a series of subsamples (e.g. Borges \& Brown, 2003; Barham \& Stewart, 2005; Maczey et al., 2005), however the potential for PSE is reduced because the motor can be idled whilst the nozzle is being lowered and raised between points (Stewart, 2002). Repeating the present study to quantify the extent of PSE with the D-vac and Vortis is feasible, but for the latter would require the use of a shorter sampling cylinder. This is because the Vortis has a wide expansion chamber above the collecting nozzle which would prevent the nozzle being placed flat on the ground against the inside edge of a tall sampling cylinder. Nonetheless, it is predicted that PSE with the Vortis would be lower than for the G-vac in the present study.

Further research might also explore the reason for the taxon-specific PSE shown with the G-vac. The finding that Auchenorrhyncha species vary in susceptibility to PSE is not surprising because all sampling methods exhibit some bias according to characteristics of the target organisms (Tormala, 1982; Cherrill \& Sanderson, 1994; Brook et al., 2008; Sanders \& Entling, 2011). The possibility that some highly mobile individuals escaped the unenclosed sample area also cannot be excluded. It would therefore be helpful to expand this investigation to include a broader range of taxa, vegetation types and sample durations. Subtle variations in the application of vacuum samplers may also have unforeseen consequences. For example, variation in the pressure used to apply the G-vac nozzle to the ground, and in speed with which the nozzle is raised and lowered between samples, may influence the risk of PSE. As suggested by Duffey (1974), specimens may be drawn in around the edge of the nozzle when it is lowered and raised during a series of touch-downs. Moreover, the suction power of G-vacs falls when the nozzle is flat on the ground because air-flow into the nozzle is reduced. Capture from within the sample area and PSE may both be greater when the nozzle is less firmly applied by the operator, and at sites with a more varied micro-topography, due to a less effective "seal" being created between the nozzle and the ground. PSE would certainly be a significant risk in studies where D-vac and G-vac nozzles have intentionally been held above the ground surface during sampling (e.g. Elliot et al., 2006; Doxon et al., 2011).

The points above form an agenda for further experimentation, while the methodology outlined provides a means of quantifying PSE and controlling for the confounding perimeter-to-area ratio effects seen in previous studies. More generally the present study suggests that use of an open-ended sampling cylinder is a simple, inexpensive and effective way of minimising peripheral suction effects which can be recommended for sampling with G-vac suction apparatus.
ACKNOWLEDGEMENTS. I am grateful to A. Broadhurst and colleagues for fabrication of prototype sampling cylinders and to S. Leather, T. Pope and R. Graham for stimulating discussions. Feedback from anonymous referees also greatly improved this paper.

\section{REFERENCES}

Barham D.F. \& Stewart A.J.A. 2005: Differential indirect effects of excluding livestock and rabbits from chalk heath on the associated leafhopper (Hemiptera: Auchenorrhyncha) fauna. J. Insect Conserv. 9: 351-361.

Bell J.R., Wheater C.P., Henderson R. \& Cullen R. 2002: Testing the efficiency of suction samplers (G-vacs) on spiders: the effect of increasing nozzle size and suction time. In Toft S. \& Scharff N. (eds): European Arachnology 2000. Aarhus University Press, Aarhus, pp. 285-290.

Biedermann R. \& Niedringhaus R. 2009: The Plant- and LeafHoppers of Germany - Identification Key to All Species. Wissenschaftlich Akademischer Buchvertrieb-Fründ, Scheeßel, 409 pp.

Borges P.A.V. \& Brown V.K. 2003: Estimating species richness of arthropods in Azorean pastures: the adequacy of suction sampling and pitfall trapping. - Graellsia 59: 7-24.

Brook A.J., Woodcock B.A., Sinka M. \& Vanbergen A.J. 2008: Experimental verification of suction sampler capture efficiency in grasslands of differing vegetation height. - J. Appl. Ecol. 45: $1357-1363$.

CherRill A.J. \& Rushton S.P. 1993: The Auchenorrhyncha of an unimproved moorland in northern England. - Ecol. Entomol. 18: $95-103$.

Cherrill A.J. \& Sanderson R.A. 1994: Comparison of sweep-net and pitfall trap sampling of moorland Hemiptera: evidence for vertical stratification within vegetation. - The Entomologist 113: $70-81$

Doxon E.D., Davis C.A. \& Fuhlendorf S.D. 2011: Comparison of two methods for sampling invertebrates: vacuum and sweepnetting. - J. Field Ornithol. 82: 60-67.

DufFey E. 1974: Comparative sampling methods for grassland spiders. - Bull. Brit. Arachnol. Soc. 3: 34-37.

Elliot N.C., Tao F.L., Fuentes-Granados R., Giles K.L., Elliot D.T., Greenstone M.H., Shufran K.A. \& Royer T.A. 2006: Dvac sampling for predatory arthropods in winter wheat. - Biol. Contr. 38: 325-330.

Henderson I.F. \& Whitaker T.M. 1977: The efficiency of an insect suction sampler in grassland. - Ecol. Entomol. 2: 57-60.

Hines J., Lynch M.E. \& Denno R.F. 2005: Sap-feeding insect communities as indicators of habitat fragmentation and nutrient subsidies. - J. Insect Conserv. 9: 261-280.

Hollier J.A., Maczey N., Masters G. \& Mortimer S.R. 2005: Grassland leafhoppers (Hemiptera: Auchenorrhyncha) as indicators of habitat condition - a comparison of between-site and between-year differences in assemblage composition. - $J$. Insect Conserv. 9: 299-307.

Hossain Z., Gurr G.M. \& Wratten S.D. 1999: Capture efficiency of insect natural enemies from tall and short vegetation using vacuum sampling. - Ann. Appl. Biol. 135: 463-467.

Littlewood N.A., Dennis P., Pakeman R.J. \& Woodin S.J. 2006: Moorland restoration aids the reassembly of associated phytophagous insects. - Biol. Conserv. 132: 395-404.

LitTlewood N.A., Pakeman R.J. \& Woodin S.J. 2009: Isolation of habitat patches limits colonisation by moorland Hemiptera. J. Insect Conserv. 13: 29-36.

Macleod A., Wratten S.D. \& Harwood R.W.J. 1994: The efficiency of a new lightweight suction sampler for sampling 
aphids and their predators in arable land. - Ann. Appl. Biol. 124: $11-17$.

Maczey N., Masters G., Hollier J.A. \& Mortimer S.R. 2005: Community associations of chalk grassland leafhoppers (Hemiptera: Auchenorryncha): conclusions for habitat conservation. - J. Insect Conserv. 9: 281-297.

Morris M.G., Clarke R.T. \& Rispin W.E. 2005: The success of a rotational grazing system in conserving the diversity of chalk grassland Auchenorrhyncha. - J. Insect Conserv. 9: 363-374.

Nickel H. \& HildebrandT J. 2003: Auchenorrhyncha communities as indicators of disturbance in grasslands (Insecta, Hemiptera) - a case study from the Elbe flood plains (northern Germany). - Agr. Ecosyst. Environ. 98: 183-199.

Rodwell J.S. 1992: British Plant Communities. Vol. 2. Grasslands and Montane Communities. Cambridge University Press, Cambridge, $552 \mathrm{pp}$.

Samu F., Nemeth J. \& Kiss B. 1997: Assessment of the efficiency of a hand-held suction device for sampling spiders: improved density estimation or oversampling? - Ann. Appl. Biol. 130: 371-378.
Samu F. \& Sarospataki M. 1995: Design and use of a hand-held suction sampler, and its comparison with sweep net and pitfall trap sampling. - Folia Entomol. Hungar. 56: 195-203.

SANDERS D. \& ENTLING M.H. 2011: Large variation of suction sampling efficiency depending on arthropod groups, species traits and habitat properties. - Entomol. Exp. Appl. 138: 234243.

StAnden V. 2000: The adequacy of collecting techniques for estimating species richness of grassland invertebrates. - J. Appl. Ecol. 37: 884-893.

SteWARt A.J.A. \& Wright A.F. 1995: A new inexpensive suction apparatus for sampling arthropods in grasslands. - Ecol. Entomol. 20: $98-102$.

SteWART A.J.A. 2002: Techniques for sampling Auchenorrhyncha in grasslands. - Denisia 4: 491-512.

ToRmala T. 1982: Evaluation of five methods of sampling field layer arthropods, particularly the leafhopper community, in grassland. - Ann. Entomol. Fenn. 48: 1-16.

Received September 8, 2014; revised and accepted April 7, 2015 Prepublished online May 15, 2015 